\title{
Monitoring wine aging with Fourier transform infrared spectroscopy (FT-IR)
}

\author{
Marianthi Basalekou ${ }^{1}$, Christos Pappas ${ }^{1}$, Yorgos Kotseridis ${ }^{1}$, Argiro Strataridaki², Efthimios Geniatakis ${ }^{2}$, Petros Tarantilis ${ }^{1}$, \\ and Stamatina Kallithraka ${ }^{1}$ \\ ${ }^{1}$ Department of Food Science \& Human Nutrition, Agricultural University of Athens, 75 Iera Odos, 11855 Athens, Greece \\ ${ }^{2}$ School of Agricultural Technology, Technological and Educational Institute of Crete, Heraklion, Crete, Greece
}

\begin{abstract}
Oak wood has commonly been used in wine aging but recently other wood types such as Acacia and Chestnut, have attracted the interest of the researchers due to their possible positive contribution to wine quality. However, only the use of oak and chestnut woods is approved by the International Enological Codex of the International Organisation of Vine and Wine. In this study Fourier Transform (FT)-mid-infrared spectroscopy combined with Discriminant Analysis was used to differentiate wines aged in barrels made from French oak, American oak, Acacia and Chestnut and in tanks with oak chips, over a period of 12 months. Two red (Mandilaria, Kotsifali) and two white (Vilana, Dafni) native Greek grape varieties where used to produce four wines. The Fourier Transform Infrared (FT-IR) spectra of the samples were recorded on a Zinc Selenide (ZnSe) window after incubation at $40^{\circ} \mathrm{C}$ for $30 \mathrm{~min}$. A complete differentiation of the samples according to both the type of wood used and the contact time was achieved based on their FT-IR spectra.
\end{abstract}

\section{Introduction}

Wine ageing in wooden barrels is one of the most common methods in the winemaking process. The wood influences the organoleptic profile of the wine through important modifications that take place during barrel aging due to the slow and continuous diffusion of oxygen through the wood pores and the extraction of many substances (e.g., aromatic compounds and ellagitannins) which modulate its sensory attributes such as aroma, structure, astringency, bitterness and color [1]. The main reasons that influence the release of wood extractable compounds is the ageing technology, involving the barrel characteristics, such as the wood botanical species [2,3], the toasting level [4] and the barrel size [5]. The quantity of the barrel extractable compounds depends mainly on the geographical origin and the type of wood used [6] the age of the barrel and the contact time between wine and wood. The most frequently used type of wood is oak, and between the species of oak used in winemaking the most important are Quercus robur that originates from France and Quercus alba that originates from the United States, studies on the chemical composition of which have demonstrated that they are quantitatively different $[7,8]$. Recently other types of wood, such as Acacia and Chestnut have been used for ageing, showing good potential for use in winemaking [9].

Sophisticated methods and instrumentation have been developed in order to facilitate the accurate and precise measurement of wood extracted compounds. Infrared spectroscopy based methods are recently emerging because of their versatility and efficiency, their cost effectiveness, and their fast and non-invasive nature [10,11]. Combining spectroscopic techniques with multivariate data analysis is proving to be very promising for the discrimination of wines of different varietal origin or wines from different countries, as was reported recently [12-14].
The aim of this paper was to find a rapid, simple and economical method for the discrimination between wines aged in different types of containers and for different time periods using Fourier transform infrared spectroscopy (FT-IR).

\section{Materials and methods}

\subsection{Wines and wood maturations}

The wines were 2013 vintage from the region of Heraklion in Crete, Greece. Two white wines from the grape varieties Vilana and Dafni and two red from Kotsifali and Mandilaria, all indigenous varieties of Crete, were used. Oenological parameters of resulting wines are shown in Table 1. French (Quercus robur) and American (Quercus alba) standard barrels (225 1) with a medium toasting were purchased from "Tonnellerie du Monde World Cooperage", Acacia standard barrels with a light plus $(\mathrm{L}+)$ toasting were purchased from Tonellerie du sud ouest, and Chestnut standard barrels with a medium toasting were purchased from Tesias Metsovo. The oak chips (French oak) were from Seguin Moreau (Oenostick ${ }^{\circledR}$, V18). All wines completed fermentation in stainless steel tanks and were then transferred to the barrels and stainless steel tanks with oak chips for maturation. Control wines were transferred in stainless steel tanks. Samples for analyses were taken from all containers after 3, 6, 9 and 12 months of maturation. Chestnut barrels were used only for the red wines.

\subsection{Sample pretreatment}

$100 \mu \mathrm{L}$ of each sample were placed on a Zinc Selenide (ZnSe) window and were incubated at $40^{\circ} \mathrm{C}$ for $30 \mathrm{~min}$. After incubation, the samples were ready for the spectroscopic analysis. 
Table 1. Oenological parameters of wine samples.

\begin{tabular}{|l|c|c|c|c|}
\hline Wine & $\begin{array}{c}\text { Ethanol } \\
\%(\mathbf{v} / \mathbf{v})\end{array}$ & $\begin{array}{c}\text { Total acidity } \\
\text { (g/L in } \\
\text { tartaric } \\
\text { acid) }\end{array}$ & $\mathbf{p H}$ & $\begin{array}{c}\text { Volatile } \\
\text { acidity } \\
\text { (g/L in } \\
\text { acetic acid) }\end{array}$ \\
\hline Vilana & 14.3 & 6.07 & 3.41 & 0.43 \\
\hline Dafni & 12.7 & 5.25 & 3.35 & 0.40 \\
\hline Kotsifali & 13.6 & 4.95 & 3.45 & 0.47 \\
\hline Mandilaria & 12.9 & 5.17 & 3.41 & 0.31 \\
\hline
\end{tabular}

\subsection{Spectroscopic analysis}

Triplicate spectra of 48 samples for red varieties and 40 samples for white varieties (88 in total) were collected with a Thermo Nicolet 6700 FT-IR spectrophotometer (Thermo Electron Corporation, MA, USA) equipped with a deuterated triglycine sulfate (DTGS) detector. The FT-IR spectra were collected using a standard ZnSe window against a ZnSe background with a total of 100 scans (resolution $4 \mathrm{~cm}^{-1}$ ) Each spectrum was smoothed using the Savitsky-Golay algorithm (5-point moving, second-degree polynomial) and its baseline was corrected (second-degree polynomial, 20 iterations). The average spectrum of each sample was calculated by means of the corresponding function of the software of the spectrometer using the software accompanying the spectrometer (OMNIC 7.3, Thermo Fisher Scientific Inc.).

\subsection{Chemometrics}

Discriminant analysis was performed using the JMP Statistical Discovery software, version 8. Spectral data were exported to JMP, and PCA was used to derive 30 principal components that ensure that $99 \%$ of the variability is considered by the analysis [20]. Subsequently, using the stepwise selection and the linear method, discriminant analysis was performed.

\section{Results and discussion}

\subsection{Spectroscopic analysis}

FT-IR spectra were obtained for the 88 samples analysed; a typical spectrum for the whole spectral range can be shown in Fig. 1 (white wines) and Fig. 2 (red wines).

The band in the $3702-3012 \mathrm{~cm}^{-1}$ region of the spectra originates from compounds with an $-\mathrm{OH}$ group, such as water [15]. Various IR bands occur in the region from 1800 to $900 \mathrm{~cm}^{-1}$, which is part of the fingerprint region, such as those corresponding to the vibration of the $\mathrm{C}-\mathrm{O}, \mathrm{C}-\mathrm{C}$, $\mathrm{C}-\mathrm{H}$ and $\mathrm{C}-\mathrm{N}$ bonds [16]. The peak centered at $1718 \mathrm{~cm}^{-1}$ is due to the stretching of carbonyl group $(\mathrm{C}=\mathrm{O})$, while the second peak at $1613 \mathrm{~cm}^{-1}$ is due to $\mathrm{C}=\mathrm{C}$ stretching (typical for aromatic molecules) [17-19]. The absorption around

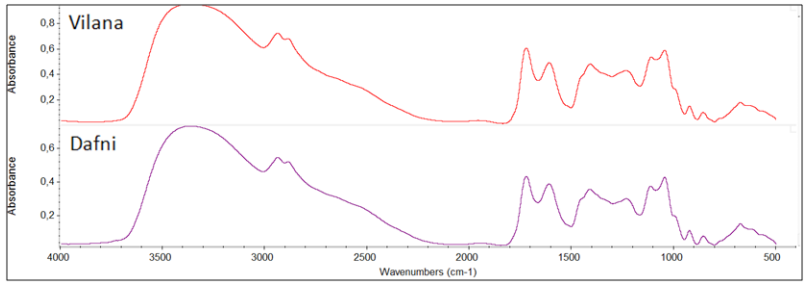

Figure 1. Typical FTIR spectra of Vilana and Dafni samples.

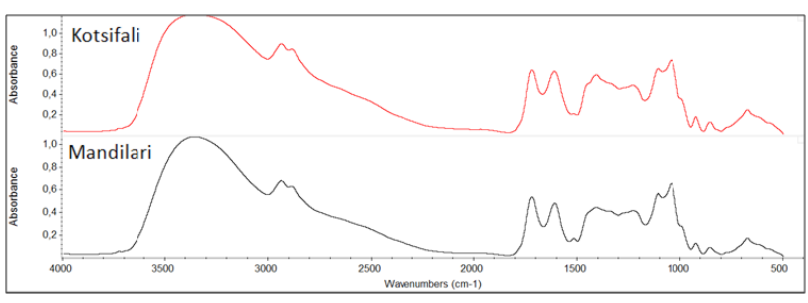

Figure 2. Typical FTIR spectra of Kotsifali and Mandilaria samples.

$1449 \mathrm{~cm}^{-1}$ corresponds to antisymmetric in-plane bending of $\mathrm{CH}_{3}$ and to deformation of $-\mathrm{CH}_{2}-$ groups $[18,19]$. The peak at $1350 \mathrm{~cm}^{-1}$ is associated with $\mathrm{CH}$ bending and $\mathrm{CH}_{2}$ waging, while peaks at $1285 \mathrm{~cm}^{-1}$ correspond to in-plane bending of O-H [16-18]. The peaks at 1204, 1114 and $1066 \mathrm{~cm}^{-1}$ correspond to the stretching vibration of $\mathrm{C}-\mathrm{O}$ [17-19].

\subsection{Discriminant analysis}

Figure 3 shows the results obtained regarding the contact time period. The results indicate a complete discrimination of $100 \%$. According to Table 2, no samples were misclassified.

Regarding the container type, Fig. 4 shows an almost complete discrimination of $95.4 \%$. In this case, there were found 4 misclassified samples (Table 3). Namely, one sample of American Oak was classified as French Oak, one sample of French Oak was classified as Chestnut, one sample of Tank was classified as Tank

Table 2. JMP discrimination results regarding time of contact.

\begin{tabular}{|l|c|c|c|c|}
\hline \multicolumn{5}{|c|}{ Counts: Actual rows by predicted columns } \\
\hline & 12 months & 3 months & 6 months & 9 months \\
\hline 12 months & 22 & 0 & 0 & 0 \\
\hline 3 months & 0 & 22 & 0 & 0 \\
\hline 6 months & 0 & 0 & 22 & 0 \\
\hline 9 months & 0 & 0 & 0 & 22 \\
\hline
\end{tabular}




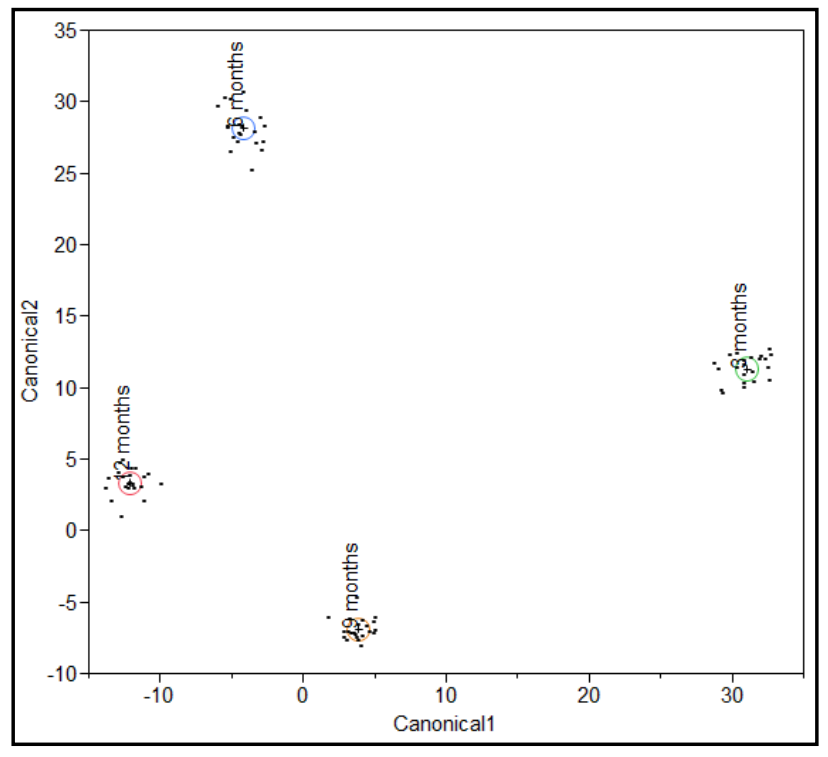

Figure 3. Discrimination results regarding time of contact.

Table 3. JMP discrimination results.

\begin{tabular}{|l|c|c|c|c|c|c|}
\hline \multicolumn{7}{|c|}{ Counts: Actual rows by predicted columns } \\
\hline & Acacia & $\begin{array}{c}\text { American } \\
\text { Oak }\end{array}$ & Chestnut & $\begin{array}{c}\text { French } \\
\text { Oak }\end{array}$ & Tank & $\begin{array}{c}\text { Tank } \\
\text { with } \\
\text { chips }\end{array}$ \\
\hline Acacia & 16 & 0 & 0 & 0 & 0 & 0 \\
\hline $\begin{array}{l}\text { American } \\
\text { Oak }\end{array}$ & 0 & 15 & 0 & 1 & 0 & 0 \\
\hline Chestnut & 0 & 0 & 8 & 0 & 0 & 0 \\
\hline $\begin{array}{l}\text { French } \\
\text { Oak }\end{array}$ & 0 & 0 & 1 & 15 & 0 & 0 \\
\hline Tank & 0 & 0 & 0 & 0 & 15 & 1 \\
\hline $\begin{array}{l}\text { Tank } \\
\text { with } \\
\text { chips }\end{array}$ & 0 & 0 & 0 & 1 & 0 & 15 \\
\hline
\end{tabular}

with Chips and one sample from Tank with Chips was classified as French Oak.

\section{Conclusion}

The objective of the research proposed was to explore the suitability of FT-IR spectroscopy for the discrimination of wines aged in different containers for different time periods. The spectroscopic analysis of the samples combined with the discriminant analysis resulted in a statistically significant discrimination of both the type of container and the time spent in it. The proposed method is promising since it is simple, rapid, economical without the requirement of chemical reagents and sample pretreatment steps.

This study was funded by the program Thalis, "Evaluation and optimization of the quality factors during maturation of wines produced from Cretan red and white grape varieties production of high quality wines".

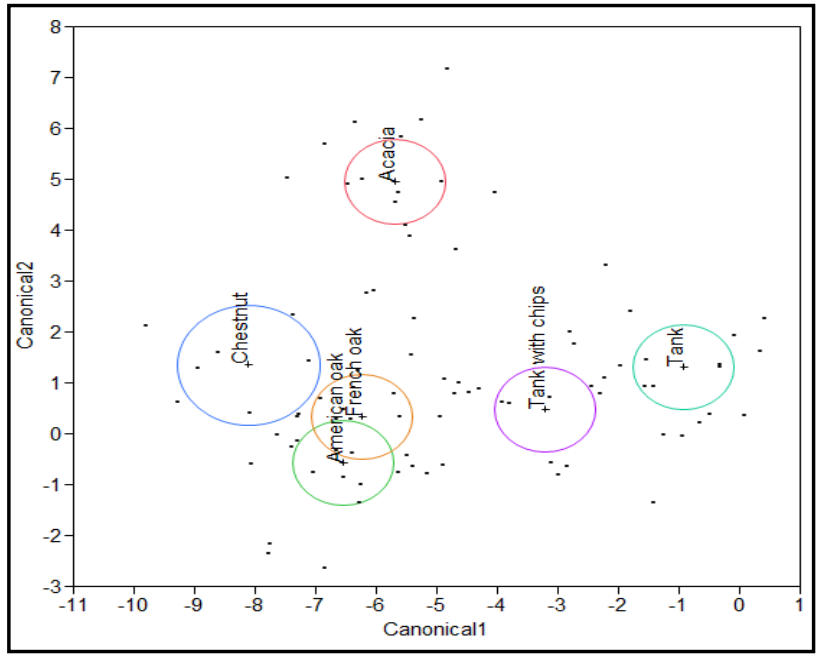

Figure 4. Discrimination results regarding container type.

\section{References}

[1] M. Del Alamo Sanza, J. A. F. Escudero, R. De Castro Torío, Food Sci. Technol. Int., 10(4), 233-241 (2004)

[2] M. T. Frangipane, D. D. Santis, A. Ceccarelli, Food Chem., 103(1), 46-54 (2007)

[3] J. Marco, J. Artajona, M.S. Larremi, F.X. Rius, Am. J. Enol.Vitic., 45, 192-200 (1994)

[4] K. Chira, P.L. Teissedre, Food Chem., 140(1-2), 168-177 (2013)

[5] B. Fernández de Simóna, E. Cadahíaa, M. del Álamob, I. Nevares, Anal. Chim. Acta 660(1-2), 211-220 (2010)

[6] J. R. Mosedale, J. L. Puech, F. Feuillat, Am. J. Enol. Vitic., 50, 503-512 (1999)

[7] V.L. Singleton, Am. J. Enol. Vitic. 46, 98-115 (1995)

[8] M.J. Cabrita, C. Barrocas Dias, A.M. Costa Freitas S. Afr. J. EnoL Vitic., 32(2), 2011

[9] M.Rosso, A. Panighel, A. Vedova, L. Stella, R. Flamini, J.Agric. Food Chem. 57(5), 1915-1920 (2009)

[10] J. Herrera, A. Guesalaga, E. Agosin, Meas. Sci. Technol., 14(5), 689-697 (2003)

[11] D. Picque, D. Lefier, R. Grappin, G. Corrieu, Anal. Chim. Acta, 279(1), 67-72 (1993)

[12] D. Cozzolino, H. E. Smyth, M. Gishen, J. Agric. Food. Chem., 5(26), 7703-7708 (2003)

[13] P.A. Tarantilis, V.E. Troianou, C.S. Pappas, Y.S. Kotseridis, M.G. Polissiou, Food Chem., 111 192-196 (2008)

[14] L. Liua, D. Cozzolinob, W.U. Cynkarb, R.G. Dambergsb, L. Janikb, B.K. O’Neilla, C.B. Colbya, M. Gishenb, Food Chem., 106(2), 781-786 (2008)

[15] Y. Zhang, J. Chen, Y. Lei, Q. Zhou, S. Sun, J. Mol. Struct., 974, 144-150 (2010)

[16] Z. Movasaghi, S. Rehman, IU. Rehman, Appl. Spectrosc. Reviews, 42, 493-541 (2007) 
[17] A. Edelmann, J. Diewok, K.C. Schuster, B. Lendl, J. Agric. Food. Chem., 49(3), 1139-1145 (2001)

[18] K. Nakanishi, P.H. Solomon, Infrared absorption spectroscopy (2nd ed.). San Francisco, Holden-Day, Inc. (1977).
[19] G. Socrates, Infrared characteristic group frequencies, Tables and charts ( $2^{\text {nd }}$ ed.). Chichester, John Wiley \& Sons Ltd (1997)

[20] H. Martens, M. Martens, Multivariate Analysis of Quality. An Introduction, New York, Wiley (2000) 